Original Article

\title{
ANTIOXIDANT ACTIVITY AND TOTAL PHENOL CONTENT OF DIFFERENT PLANT PARTS OF LEBANESE ANNONA SQUAMOSA LINN.
}

\author{
FARAH IBRAHIMa, ALI JABER ${ }^{\text {* }}$, GHASSAN IBRAHIM ${ }^{b}$, EDMOND CHEBLE $^{b}$
}

aInstitut de Chimie Organique et Analytique, Universite d'Orleans, CNRS FR 2708, UMR7311, Orleans, France, bLaboratoire de Recherche et Developpement des Medicaments et des Produits Naturels (RDMPN), Faculty of Pharmacy, Lebanese University, Beirut, Lebanon Email: ali.jaber.2@ul.edu.lb

Received: 31 Jan 2020, Revised and Accepted: 22 Jun 2020

\section{ABSTRACT}

Objective: The aim of this work was to characterize the antioxidant properties and to evaluate the total phenol content of leaves, bark, pericarp, and pulp extracts of Lebanese Annona squamosa Linn. (A. squamosa),, as well as a total screening of secondary metabolites present in the various plant parts studied.

Methods: Two solvent systems were used for extraction: ethanol $80 \%$ and methanol $80 \%$. The antioxidant activity of different extracts was investigated using 1,1-diphenyl-2-picrylhydrazyl (DPPH) assay. The Total Phenol Content (TPC) of the different plant parts are determined and compared via Folin-Ciocalteu method. The results were presented as the mean of three separate experiments and error bars were used to illustrate standard deviation.

Results: The phenolic content was found to be highest in the A. squamosa leaves methanolic and ethanolic extracts (117.2 mg and 112.92 gallic acid extract/g, respectively). The results showed that $A$. squamosa leaves methanolic and ethanolic extracts display the highest antioxidant activities than the bark, pulp and pericarp extracts, with half-maximal inhibitory concentration values 13.61 and $15.97 \mu \mathrm{g}$. ml ${ }^{-1} \mathrm{respectively}$. Ethanol $80 \%$ and methanol $80 \%$ were found to be efficient for the extraction of phenolic compounds.

Conclusion: Results of this study indicate the presence of promising compounds in Lebanese A. squamosa that are able to act as antioxidants and free radical scavengers.

Keywords: Annona squamosa, Antioxidant, DPPH, Phytochemical screening, Total phenol content

(C) 2020 The Authors. Published by Innovare Academic Sciences Pvt Ltd. This is an open access article under the CC BY license (http://creativecommons.org/licenses/by/4.0/) DOI: http://dx.doi.org/10.22159/ijpps.2020v12i8.36992. Journal homepage: https://innovareacademics.in/journals/index.php/ijpps.

\section{INTRODUCTION}

Free radicals are the inevitable by-products resulting from biological redox reactions. At high concentrations, they produce oxidative stress, a harmful process that can damage cell function and structures. They have been reported to inactivate enzymes and damage important cellular components causing tissue injury through covalent bond and lipid peroxidation [1]. Research in the medical field reports the implication of free radicals induced oxidative stress in the development of many diseases such as inflammatory diseases, atherosclerosis, aging, diabetes, and cancer [2-4]

The antioxidants are associated with the reduction of free radical generation. Thus, it may be beneficial to recover normal function and treat such diseases. Antioxidants are a crucial defense against free radical-induced damage and are critical in maintaining optimum health and wellbeing [5]. In recent years, there has been an increased interest in the therapeutic use of antioxidants in the treatment of diseases associated with oxidative stress. Antioxidantrich diet and natural antioxidant supplements as part of a healthy lifestyle are now being recognized to protect health from oxidative stress [6]. Plants and other organisms have evolved a wide range of mechanisms to surmount this problem with a wide variety of antioxidants for molecules and enzymes $[7,8]$.

Annona squamosa Linn. (A. squamosa) is a small, well-branched tree of the family of Annonaceae. The plant is native to the tropical Americas and is cultivated mainly for its edible fruit commonly called "sugar apple". It was later taken to the Philippines and Asia via West Indies. A. squamosa grows at altitudes of 0 to $2,000 \mathrm{~m}$ and does well in hot, dry climates; at much lower altitudes than many of the other fruit bearers in its family $[9,10]$. In Lebanon, the $A$. squamosa crop is gaining in popularity and has been cultivated along the coastal zone at an altitude of $0-200 \mathrm{~m}$ above sea level [11]. Al parts of $A$. squamosa tree are traditionally used to treat various diseases [12]. It is considered to be a good source of natural antioxidants for various diseases [13]. It has been reported to possess a wide variety of pharmacological activities [14-18].

Therefore, this investigation was carried out to study the phytochemical screening, evaluate the total phenol content and investigate the antioxidant potential of Lebanese A. squamosa. Another aim of this research was to compare the two solvent systems in terms of their extraction efficacy of potent antioxidants compounds from different parts of $A$. squamosa plant.

\section{MATERIALS AND METHODS}

Chemicals

Ethanol and methanol used in this study were analytical grade and purchased from Sigma-Aldrich, Lebanon. All chemicals 1,1-diphenyl2-picrylhydrazyl (DPPH), gallic acid (GA) powder, Folin-Ciocalteu's Reagent (FCR), sodium bicarbonate, iron chloride, magnesium shavings, ammonium acetate buffer, sulfuric acid, hydrochloric acid used were purchased from VWR, Lebanon. The water used in all procedures was a distilled one and obtained from TKA MICROMED apparatus for water distillation.

\section{Apparatus}

All samples were weighed using a RADWAG XA 82/220/2X laboratory balance. The dried leaves and the dry bark were ground using a POLYMIX grind mill. The extracts were concentrated using a HEIDOLPH rotavapor apparatus. After evaporation, aqueous parts of the frozen extracts were removed using a CHRIST freeze dryer machine. The absorbance values of the solutions were measured using a VWR UV-6300PC double beam spectrophotometer.

Collection and preparation of plant material

The samples of $A$. squamosa plants studied in this work were collected directly from the producer who owned the trees. The trees were grown in Batroun, a coastal city in northern Lebanon, which rises 80 to 
$100 \mathrm{~m}$ from sea-level. The plant has been identified by Pr. Jean HABIB (Professor of Pharmacognosy at the Lebanese University) and confirmations were done through the Flora of the presidency of Madras, by Gamble J. S. 1921 [19]. The voucher specimens (No. 18031804) are deposited at Pharmacognosy Departement, Faculty of Pharmacy of the Lebanese University (fig. 1).

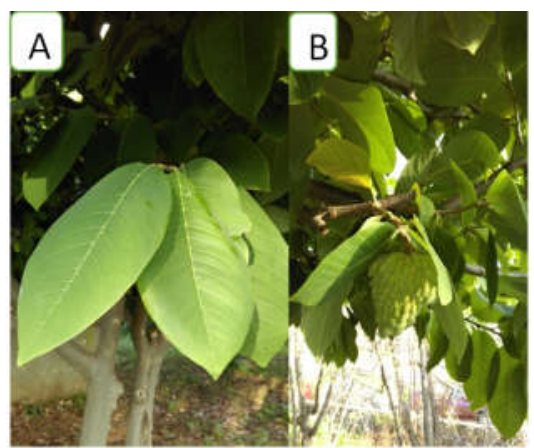

Fig. 1: A. squamosa: the appearance of leaves (A) and fruit (B)

A. squamosa leaves and bark were collected in the month of February and the beginning of March 2018 from Annona trees. The fruit was collected in the month of January 2018. Different plant parts, namely bark and leaves, were isolated from $A$. squamosa tree. Different fruit parts, namely pulp, and pericarp were isolated. The leaves were either used as fresh or shade dried on a well-ventilated rack for $3 \mathrm{w}$. The bark was also shade dried for two months. The dried samples were ground separately into fine powder and stored at room temperature for further use.

\section{Preparation of plant extracts}

Two solvents systems were used for the extraction: $80 \%$ methanol ( $\mathrm{v} / \mathrm{v}$ in water) and $80 \%$ ethanol ( $/ \mathrm{v}$ in water). A. squamosa plant extracts were obtained by macerating $20 \mathrm{~g}$ finely cut fresh leaves $/ 20$ g pulverized dried leaves/20 g pulverized dried bark/96 g pericarp, or $96 \mathrm{~g}$ pulp (filtrated using filter paper) with frequent agitation for $24 \mathrm{~h}$ with $100 \mathrm{ml}$ of the solvent system. The obtained extracts were then filtered twice through Whatman's filter paper No. 1 and the filtrates were concentrated under vacuum using a rotary evaporator at 40 ?. The condensed extracts were put in the refrigerator at- $20^{\circ} \mathrm{C}$ and then lyophilized to obtain a solid residue. The extracts were labelled and stored at room temperature in tightly closed glass containers for further analysis. The extraction yield (mg of dry extract per $\mathrm{g}$ of sample) was determined.

\section{Phytochemical screening}

Prepared plant extracts were analyzed for the presence or absence of chemical constituents like hydrolyzable and condensed tannins, flavonoids, and saponins. Alkaloids tests were performed directly on the plant material. The change of color or formation of precipitate was observed when the test reagent was added to the prepared sample for the phytochemical test. The result was recorded as present $(+)$ or absent $(-)$ depending on the outcome of the test. All the experiments were executed in triplicates.

\section{Determination of total phenol content (TPC)}

Total phenolic contents of $A$. squamosa parts were estimated using the Folin-Ciocalteu reagent based spectrophotometric assay [20] Gallic acid is used as a standard for determining the phenol content of various extracts. For this purpose, $100 \mu \mathrm{l}$ of different concentrations $\left(0.5-0.88 \mathrm{~g}^{-\mathrm{ml}^{-1}}\right)$ of the test extract solutions were combined with $0.5 \mathrm{ml}$ of Folin-Ciocalteu reagent $(2 \mathrm{~N})$ and the mixture was incubated for $5 \mathrm{~min}$ in the dark. Then, $2 \mathrm{ml}$ of sodium carbonate aqueous solution $(7 \% \mathrm{w} / \mathrm{v})$ was added. Samples were incubated in darkness for $30 \mathrm{~min}$ at room temperature. The absorbance of the reaction mixture was measured at $760 \mathrm{~nm}$ against a blank using a UV-VIS spectrophotometer. Distilled water and $2 \mathrm{ml}$ of $\mathrm{Na}_{2} \mathrm{CO}_{3}$ solution acted as a blank. A standard curve was plotted using different concentrations of gallic acid. The absorbance obtained was converted to gallic acid concentration using gallic acid standard curve. The total phenolic content was calculated as mg of gallic acid extract (GAE) per g of dry A. squamosa extract using the following formula (1):

$$
\mathrm{GAE}=\frac{\mathrm{C}(\mathrm{mg} / \mathrm{ml}) \text { ofgallic acid } \times \operatorname{vol}(\mathrm{ml})}{\mathrm{m}(\text { grams })}(1)
$$

Where: $-\mathrm{GAE}=$ mg equivalent of GAE per gram of dry extract used.

$-\mathrm{C}$ is the concentration of gallic acid $\left(\mathrm{mg} . \mathrm{ml}^{-1}\right)$ calculated by the calibration curve regression equation.

$-\mathrm{V}$ is the volume of plant extract solution

$-m$ is the mass of a plant extract used to prepare the test extract solution used.

Further calculations were done to obtain the total phenol content in mg GAE per gram of initial plant and fruit part used.

\section{Determination of antioxidant activity}

The antioxidant activities of $A$. squamosa dried leaves, fresh leaves, dried bark, pulp, and pericarp of the fruit were assessed using DPPH assay as described by Kumawat et al. [21]. $1 \mathrm{ml}$ of the methanolic extract solutions of different concentrations (0.001-0.26 mg. ml-1) was added to $1 \mathrm{ml}$ of a methanolic solution of DPPH $(81.14 \mu \mathrm{M})$ in a test tube, followed by vigorous stirring. After $30 \mathrm{~min}$ of incubation in the dark, the decrease in absorbance of each mixture (due to quenching of DPPH free radicals) was determined at $517 \mathrm{~nm}$ against a blank (methanol) using a UV-VIS spectrophotometer. The percentage scavenging activity of the DPPH radicals was calculated according to the following formula (2):

$$
\% \text { DPPH scavenging activity }=\frac{\text { Acontrol }- \text { Asample }}{\text { Acontrol }} \times 100(2)
$$

Where: $-\mathrm{A}_{\text {control }}$ is the absorbance of the mixture of methanol and DPPH solution

-Asample is the absorbance of the mixture of the sample extract/standard and DPPH solution.

Based on graphic values of the percentage of DPPH inhibition vs extract concentration, the half-maximal inhibitory concentration $\left(\mathrm{IC}_{50}\right.$ ) (the concentration of the extract needed to inhibit the $50 \%$ of the DPPH) of each extract was estimated. The antioxidant activities of all the samples were compared to the antioxidant activity of ascorbic acid, i.e. ascorbic acid was used as a reference standard.

\section{Statistical analysis}

The experimental runs and the analyses were carried out in triplicate. The experimental results derived in the study were expressed as the mean \pm standard deviation (SD). Linear regression analysis was used to calculate the $\mathrm{IC}_{50}$ values. Data were analyzed through independent samples t-test using SPSS statistics 9.0 software, the same software was used to test $\mathrm{IC}_{50}$.

\section{RESULTS AND DISCUSSION}

\section{Extraction yields}

The extraction yield depends on the nature of the solvent, the time, the temperature and the chemical nature of the sample used [22]. It is calculated as $\% \mathrm{w} / \mathrm{w}$ (weight of extract/weight of plant material). In the present study, the obtained extraction yields for the two solvent systems used namely methanol $80 \%$ and ethanol $80 \%$ are listed in table 1 . Although a number of factors have to be considered when selected the appropriate solvent, ethanol was investigated to test the possibility to replace methanol in order to reduce the toxicity. Knowing that same conditions of time and temperature were applied for the same plant part used during extraction, methanolic system was more effective in extraction compared to ethanol in the case of fresh leaves and dried bark. While ethanolic system was the suitable solvent for the extraction of pericarp. No significant difference is detected in the case of dried leaves and pulp $(\mathrm{P}<0.05)$. 
Table 1: Extraction yield and morphology of different $A$. squamosa plant parts using ethanol and methanol

\begin{tabular}{llll}
\hline Plant part & Solvent & Morphology & Extraction yield (\%w/w) \\
\hline Dried leaves & Methanol 80\% & Powder & 10.46 \\
& Ethanol 80\% & Powder & 10.57 \\
Fresh leaves & Methanol 80\% & Semi-solid & 7.00 \\
& Ethanol 80\% & Semi-solid & 3.30 \\
Dried bark & Methanol 80\% & Powder & 14.80 \\
& Ethanol 80\% & Powder & 10.92 \\
Pulp & Methanol 80\% & Powder & 19.67 \\
& Ethanol 80\% & Powder & 19.25 \\
Pericarp & Methanol 80\% & Powder & 15.41 \\
& Ethanol 80\% & Powder & 17.99 \\
\hline
\end{tabular}

\section{Results of phytochemical screening}

The results of the phytochemical qualitative analysis are reported in table 2 and table 3 . The screening test showed the presence of flavonoids and alkaloids in all studied extracts of A. squamosa. Also, hydrolyzable tannins were absent in all studied extracts. Condensed tannins were absent in pulp extract, but were present in all other extracts and mostly abundant in fresh and dried leaves extracts. Dried bark and leaves were rich in alkaloids. Besides the fact that ethanol is not more polar than methanol, it is worth noting that no difference was revealed in terms of families of secondary metabolites extracted. In addition, our results are in good agreement with the experimental data of Sabbah et al. [23] and Mahawar et al. [24].

Table 2: Alkaloids screening of $A$. squamosa plant.

\begin{tabular}{lll}
\hline Plant part & Alkaloids (Dragendorff reagent) & Alkaloids (Buchardart reagent) \\
\hline Dried leaves & +++ & ++ \\
Dried bark & +++ & ++ \\
Pulp & + & + \\
Pericarp & + & + \\
\hline
\end{tabular}

+++: Strong intensity reaction,++: Medium intensity reaction,+: Weak intensity reaction

Table 3: Preliminary phytochemical screening of methanolic and ethanolic extracts of $A$. squamosa plant

\begin{tabular}{lllll}
\hline Plant part & Hydrolyzable tannins & Condensed tannins & Flavonoids \\
\hline Dried leaves & - & +++ & + & + \\
Fresh leaves & - & ++++ & + & + \\
Dried bark & - & + & + & + \\
Pulp & - & - & + & - \\
Pericarp & - & + & + \\
\hline
\end{tabular}

++++: Strong intensity reaction,++: Medium intensity reaction, +: Weak intensity reaction, -: absent

\section{Total phenol content (TPC)}

Plants contain many phenolic compounds which interrupt chain oxidation reactions by donation of a hydrogen atom or chelating metals. So they act as reducing agents and antioxidants [25]. Fig. 2 shows the total phenol of methanolic and ethanolic extracts of Annona squamosa, leaves, bark, pulp and pericarp. The total phenol content is expressed in mg equivalent G. A./gram of plant part. The results showed that the different plant extracts contain relatively high contents of total phenols ranging between 1.12 and $117.19 \mathrm{mg} \mathrm{GAE} / \mathrm{g}$ plant part.

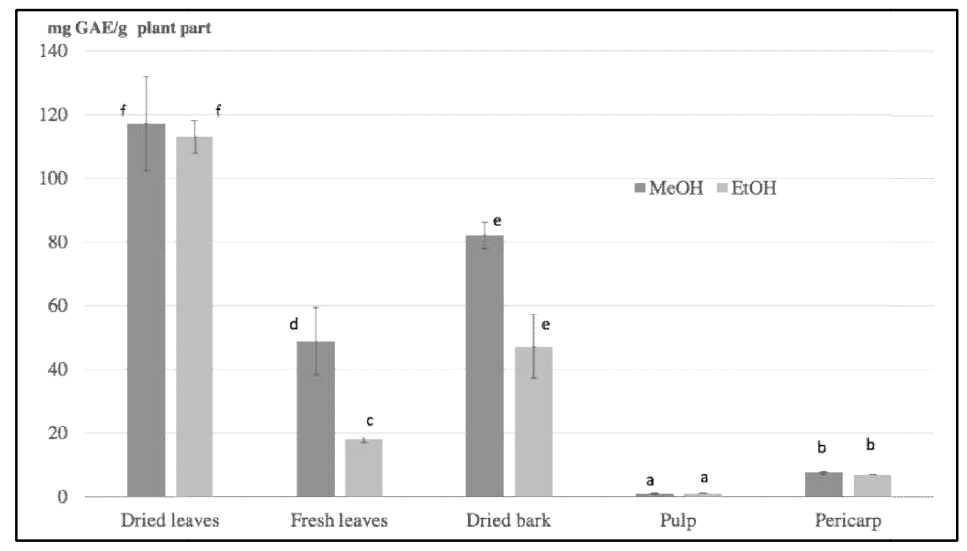

Fig. 2: Total phenol content of different extracts, (values are expressed as means \pm standard deviation ( $n=3$ ), values marked by the same letter are not significantly different $(P<0.05))$ 
The highest amounts of total phenolic content were 117.2, 112.9, $82.2 \mathrm{mg}$ gallic acid extract/g plant part and they correspond respectively to $A$. squamosa dried leaves methanolic extract, dried leaves ethanolic extract and bark methanolic extract. The bark ethanolic extract as well as the methanolic and ethanolic extract of $A$ squamosa fresh leaves, showed moderate amounts of TPC of 47.02, 48.85 , and $17.96 \mathrm{mg}$ gallic acid extract/g plant part respectively. The lowest amounts of TPC recorded were 7.7, 7.0,1.1, $1.2 \mathrm{mg}$ gallic acid extract/g plant part for methanolic, ethanolic extracts of pericarp and pulp, respectively.

The conducted work showed no significant difference in the total phenol content between methanolic and ethanolic extract of $A$. squamosa dry leaves, dry bark, pulp and pericarp $(\mathrm{P}<0.05)$. In these cases, ethanol can effectively substitute methanol in the extraction of polyphenols from these plant parts. However, extraction solvents, methanol and ethanol, significantly affected the amount of total $A$. squamosa fresh leaves phenolic compounds. Methanol was found to be more efficient in the extraction of phenolic compounds from fresh leaves than ethanol $(\mathrm{P}>0.05)$.

\section{Radical scavenging activity}

DPPH radical scavenging activity assays of the 10 different extracts of $A$. squamosa plant parts extracted by both ethanol and methanol showed significant DPPH radical scavenging activity in a concentration-dependent manner. The results revealed that the antioxidant activity increased with the concentration of the extracts DPPH free radical scavenging assays were repeated in triplicate. The half-maximal inhibitory concentration (IC50) values were determined as the concentration of the test mixture that gave 50\% reduction in absorbance from that of the control and the mean was calculated (fig. 3)

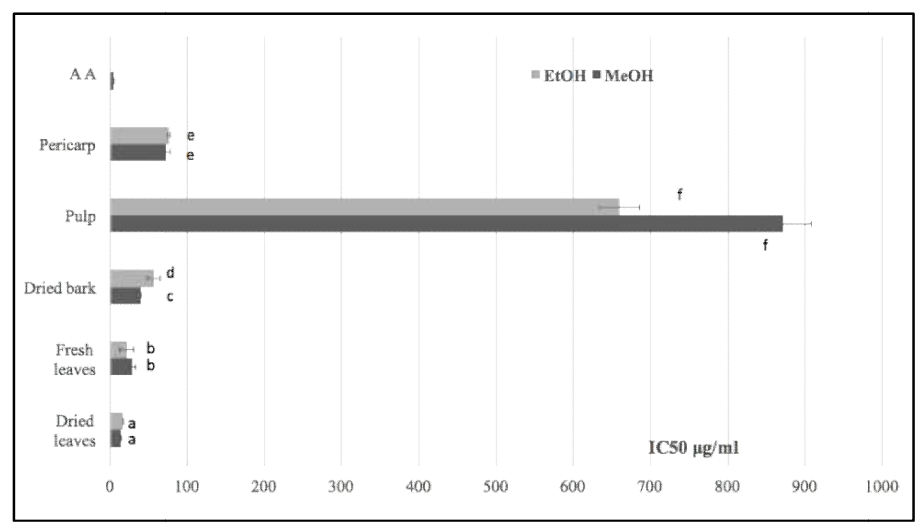

Fig. 3: DPPH radical scavenging activity of different $A$. Squamosa extracts (Values are expressed as means \pm standard deviation (n=3), values marked by the same letter are not significantly different $(P<0.05))$

The potent free radical scavenging activity was exhibited by the methanolic extract of dried leaves ( $\mathrm{IC}_{50}=13.61 \mu \mathrm{g} / \mathrm{ml}$ ), whereas the ethanolic extract exhibited relatively less free radical scavenging activity $\left(\mathrm{IC}_{50}=15.97 \mu \mathrm{g} / \mathrm{ml}\right)$.

The $\mathrm{IC}_{50}$ values of the fresh leaves ethanolic and methanolic extracts were $20.75 \mu \mathrm{g} / \mathrm{ml}, 27.35 \mu \mathrm{g} / \mathrm{ml}$, respectively. The $\mathrm{IC}_{50}$ values of the dried bark ethanol and methanol extracts were $55.77 \mu \mathrm{g} / \mathrm{ml}$, $38.49 \mu \mathrm{g} / \mathrm{ml}$, respectively. The $\mathrm{IC}_{50}$ values of the pericarp ethanol and methanol extracts were $76.47 \mu \mathrm{g} / \mathrm{ml}, 70.91 \mu \mathrm{g} / \mathrm{ml}$ respectively. The poorest free radical scavenging activity was recorded for the methanolic extract $\left(\mathrm{IC}_{50}=871.33 \mu \mathrm{g} / \mathrm{ml}\right)$ and the ethanolic extract $\left(\mathrm{IC}_{50}=659.68 \mu \mathrm{g} / \mathrm{ml}\right.$ ) of pulp. However, ascorbic acid showed the highest DPPH radical scavenging activity $\left(\mathrm{IC}_{50}=6.62 \mu \mathrm{g} / \mathrm{ml}\right)$. The conducted work proved no significant difference in scavenging activity between methanol and ethanol extract of $A$. squamosa dry and fresh leaves, pericarp and pulp $(\mathrm{P}<0.05)$. However, A. squamosa bark methanol extract exhibited significantly higher scavenging activity than ethanol extract $(\mathrm{P}>0.05)$

To the best of our knowledge, there is no study available that has focused upon different parts of A. squamosa grown in Lebanon. On the other hand, only few studies compared the TPC of different parts extracts of $A$. squamosa cultivated in other places in the world. Our results are very consistent with a result reported by Montero Fernandez et al. [26] which states that $A$. squamosa pericarp extract is more rich in TPC than pulp. In another work, Mariod et al evaluated the total phenol content and antioxidant activities of $A$. squamosa leaves and bark methanolic extracts and determined by the DPPH technique $\mathrm{IC}_{50}$ values of 7.81 and $125.0 \mu \mathrm{g} . \mathrm{ml}^{-1}$, respectively. This result is close to the one found in this work in the case of the leaves methanolic extract, but greater than that found in the present study for the bark methanolic extract [27].

The results were also expressed as ascorbic acid equivalent antioxidant capacity (AEAC) (table 4) i.e. mg ascorbic acid equivalents/mg dry wt, which was calculated as follows: [28]

$$
\frac{\mathrm{IC}_{50} \text { ascorbic acid }\left(\frac{\mathrm{mg}}{\mathrm{ml}}\right)}{\mathrm{IC}_{50} \text { sample }\left(\frac{\mathrm{mg}}{\mathrm{ml}}\right)}=\frac{\mathrm{X} \mathrm{mg} \text { ascorbic acid equivalent }}{\mathrm{mg} \mathrm{dry} \mathrm{wt}}(3)
$$

where $\mathrm{IC}_{50}$ ascorbic acid and $\mathrm{IC}_{50}$ sample are the effective concentrations of the ascorbic acid and the sample respectively. The higher the AEAC value, the greater is the antioxidant activity.

Table 4: Ascorbic acid equivalent antioxidant capacity AEAC (mg AAE/mg dry wt)

\begin{tabular}{|c|c|c|}
\hline & $\mathrm{MeOH}$ & EtOH \\
\hline Dried leaves & 0.233 & 0.198 \\
\hline Fresh leaves & 0.116 & 0.153 \\
\hline Dried bark & 0.082 & 0.057 \\
\hline Pulp & 0.004 & 0.005 \\
\hline Pericarp & 0.045 & 0.041 \\
\hline
\end{tabular}

The methanolic dried leaves extract showed the highest AEAC value of $0.233 \mathrm{mg} \mathrm{AAE} / \mathrm{g}$ dry wt of extract. Polyphenolic compounds have been reported to have antioxidant activities due to the reactivity of the phenolic moiety, scavenging free radicals via electron donation or hydrogen donation [29]. Hence, the antioxidant activities of dried leaves come to confirm these reports. $\mathrm{IC}_{50}$ and $\mathrm{AEAC}$ values obtained 
for methanolic dried leaves extract imply that the extract contains phytochemicals with antioxidant properties.

\section{Correlation between TPC and antioxidant activity}

Several studies have evaluated the relationship between the antioxidant activity of plant products and their phenolic content. It has been reported that phenolic compounds were the main antioxidant components, and their total contents were directly proportional to their antioxidant activity [30,31]. This is demonstrated in our study as far as A. squamosa dried leaves and bark extracts were concerned. These showed the highest TPC, the highest antioxidant activity as well as the highest AEAC. Regarding fresh leaves, they showed a TPC lower than dried leaves and comparable to dried bark. At the same time they showed a relatively higher antioxidant activity as well as higher ascorbic acid equivalent antioxidant capacity than dried bark. These results might be due to several reasons. The antioxidant activity of an extract is not only determined by the phenolics. Non-phenolic compounds could show more potent antioxidant activities. This is the concept of electron donor and acceptor which plays a very important role in the redox reaction so any functional group capable to donate an electron may act as a good antioxidant agent. For instance, the antioxidant activity of polysaccharides is shown to be related to their functional groups such as hydroxyl, amino, carbonyl, and carboxyl group [32]. Therefore, it is possible that fresh leaves contain nonphenolic antioxidants contributing to its antioxidant activity. Hence emerges the necessity of identification of various constituents of fresh leaves and bark through chromatographic techniques, for instance, and highlighting those responsible for antioxidant action.

\section{CONCLUSION}

In the present study, it is observed that the different parts of $A$. squamosa plant present a good contribution of phenolic compounds as well as high antioxidant activity. A. squamosa leaves showed a high total phenolic content and antioxidant activity compared to burk, pulp, and pericarp. Studies on A. squamosa anticancer and other biological properties are ongoing. However, outcomes encourages further investigations to identify the chemical constituents that are responsible for multiple biological activities.

\section{ACKNOWLEDGEMENT}

The authors are grateful to the Lebanese University; the Faculty of Pharmacy department-Lebanon-for providing all chemicals necessary to carry out this project. The authors are also grateful to Pr. Jean Habib for identifying the plant material and his constructive comments.

Farah Ibrahim and Ali Jaber performed the experimental part, calculations, data interpretation, wrote and revised the manuscript. Edmond Cheble and Ghassan Ibrahim conceived the study, design the experiments, and support the critical revision.

\section{FUNDING}

Nil

\section{AUTHORS CONTRIBUTIONS}

All authors had equally contributed to the work.

\section{CONFLICTS OF INTERESTS}

Declared none

\section{REFERENCES}

1. Aldred EM. Pharmacology: a handbook for complementary healthcare professionals. 1st ed. Edinburgh: Churchill Livingstone; 2009.

2. Khanna RD, Karki K, Pande D, Negi R, Khanna RS. Inflammation, free radical damage, oxidative stress and cancer. Interdiscip J Micro inflammation 2014;1:109.

3. Kukreja RC, Hess ML. The oxygen free radical system: from equations through membrane-protein interactions to cardiovascular injury and protection. Cardiovasc Res 1992;26:641-55.

4. Valko M, Leibfritz D, Moncol J, Cronin MTD, Mazur M, Telser J. Free radicals and antioxidants in normal physiological functions and human disease. Int J Biochem Cell Biol 2007;39:44-84.
5. Birben E, Sahiner UM, Sackesen C, Erzurum S, Kalayci O. Oxidative stress and antioxidant defense. World Allergy Organ J 2012;5:9-19.

6. Sen S, Chakraborty R. The role of antioxidants in human health. In: Silvana A, Hepel M. editors. Oxidative stress: diagnostics, prevention, and therapy. Washington, DC: American Chemical Society; 2011. p. 1-37.

7. Pratt DE. Natural antioxidants from plant material. In: Huang MT, Ho CT, Lee CY. editors. Phenolic compounds in food and their effects on health II, Antioxidants and cancer prevention. Washington, DC: American Chemical Society; 1992. p. 54-71.

8. Lobo V, Patil A, Phatak A, Chandra N. Free radicals, antioxidants and functional foods: Impact on human health. Pharmacogn Rev 2010;4:118-26.

9. Agrawal M, Agrawal Y, Itankar P, Patil A, Kelkar A, Vyas J. Pharmacognostical evaluation of Annona squamosa linn. Int Phytomed 2011;3:480-5.

10. Natural Resources Conservation Service (NRCS). Plants profile Annona squamosa $L$. united states department of agriculture; 2008. p. 4-17.

11. Yassine F, Sassine YN. State of annona cultivation in Lebanon. Master thesis, plant production, lebanese university, faculty of agriculture and veterinary sciences; 2014.

12. Gajalakshmi S, Divya R, Deepika VD, Mythili S, Sathiavelu A. Pharmacological activities of Annona squamosa: a review. Int J Pharm Sci Rev Res 2011;10:24-9.

13. Vikas B, Akhil BS, Remani P, Sujathan K. Free radical scavenging properties of Annona squamosa. Asian Pac J Cancer Prev 2017;18:2725-32.

14. Zahid M, Arif M, Rahman MA, Mujahid M. Hepatoprotective and antioxidant activities of Annona squamosa seed extract against alcohol-induced liver injury in sprague dawley rats. Drug Chem Toxicol 2018;9:1-7.

15. Salman HA, Senthilkumar R. Antibacterial activity of annona squamosa $l$. and annona reticulata $l$. against clinical isolates of mutans streptococci the causative agents of dental caries. Asian J Pharm Clin Res 2015;8 Suppl 4:152-5.

16. Elumalai N, Parameswaran I, Panchanatham ST. Anticancer effect of methanolic extract of annona squamosa on mammary carcinoma in rats with reference to glycoprotein components, lysosomal, and marker enzymes. Asian JPharm Clin Res 2017;10 Suppl 9:180-5.

17. Chakraverty $\mathrm{R}$, Bhattacharya A. The pharmacological properties of Annona squamosa linn: a review. IJPE 2016;4:692-9.

18. Kachhawah JBS, Sharma N, Tyagi S, Sharma KK. Screening of stem bark methanol extract of Annona squamosa for antibacterial activity. Int J Curr Pharm Res 2012;4:48-50.

19. Gamble JS. Flora of the presidency of madras. London: West, Newman and Adlard; 1921.

20. Singleton VL, Rossi JA. Colorimetry of total phenolics with phosphomolybdic phosphotungstic acid reagents. Am J Enol Vitic 1965;16:144-58.

21. Kumawat BK, Gupta M, Singh T, Singh Y. Free radical scavenging effect of various extracts of leaves of Balanites aegyptiaca (L.) delile by DPPH method. Asian J Plant Sci Res 2012;2:323-9.

22. El-Chaghaby GA, Ahmad AF, Ramis ES. Evaluation of the antioxidant and antibacterial properties of various solvents extracts of Annona squamosa L. leaves. Arabian J Chem 2014;7:227-33.

23. Sabbah A, Nasser M, Hijazi A, Rammal A, Nasser G. Phytochemical screening and cytotoxic activity of two extracts from seeds of Lebanese Annona squamosa L. Int J Pharma Res Health Sci 2017;5:1586-91.

24. Mahawar V, Patidar K, Joshi N. Development and evaluation of an herbal antiaging cream formulation containing Annona squamosa leaf extract. Asian J Pharm Clin Res 2019;12:210-4.

25. Kaurinovic B, Vastag D. Flavonoids and phenolic acids as potential natural antioxidants. In: Antioxidants; Shalaby E. editors. IntechOpen: London, UK; 2019.

26. Fernandez IM, Chagas EA, Filho AAM, Saravia SAM, Carvalho Dos Santos R, Cardoso PC, et al. Evaluation of total phenolic compounds and antioxidant activity in amazon fruit. Chem Eng Trans 2018;64:649-54. 
27. Mariod AA, Abdelwahab SI, Elkheir S, Ahmed JM, Fauzi PNM, Chuen ChS. Antioxidant activity of different parts from Annona squamosa, and Catunaregam nilotica methanolic extract. Acta Sci Pol Technol Aliment 2012;11 Suppl 3:249-57.

28. Leong LP, Shui G. An investigation of antioxidant capacity of fruits in singapore markets. Food Chem 2002;76:69-75.

29. Jayaprakasha GK, Patil BS. In vitro evaluation of the antioxidant activities in fruit extracts form citron and blood orange. Food Chem 2007;101:410-8.
30. Cai YZ, Luo Q, Sun M, Corke H. Antioxidant activity and phenolic compounds of 112 traditional Chinese medicinal plants associated with anticancer. Life Sci 2004;74:2157-84.

31. Liu HY, Qiu NX, Ding HH, Yao RQ. Polyphenols content and antioxidant capacity of 68 Chinese herbals suitable for medical or food uses. Food Res Int 2008;41:363-70.

32. Salas Coronado R, Villanueva Canongo C, Hernandez Carlos B. Antioxidant compounds and their antioxidant mechanism. In: Antioxidants, Shalaby E. Ed. IntechOpen: London, UK; 2019. 